\title{
Technology and Marginalization: A Case Study of the Limited Adoption of the Intranet at a State-owned Organization in Rural Australia
}

\author{
Niranjala D. Weerakkody \\ Deakin University, Geelong, VIC, Australia
}

\author{
ninaw@deakin.edu.au
}

\begin{abstract}
Taking a critical theory approach and the pluralist view of technology, this paper examines the problems in organizational communication that arose due to the implementation of a limited intranet electronic mail system as the main channel of communication between a rural stateowned organization and its city-based Head Office, installed at the sole discretion of the latter. The intranet was provided only to the administration division and managers of some units due to financial constraints. This required others to receive information carried via the intranet through a gatekeeper who due to information and work overload, failed to disseminate the information effectively and efficiently. Using a combination of qualitative data collection methods, this study found that the intranet had marginalized those without access to it and reinforced the privileged position of those already with higher status within the organization, contrary to the utopian predictions of new technologies as leading to social equality.
\end{abstract}

Keywords: Intranet, Adoption of new technologies, Digital Divide, Technology and marginalization, Critical theory and technology, pluralist view of technology, Failed adoption of a technology, Organizational Communication, Gatekeeping, Technology and power, Technology and status.

\section{Introduction}

Every organization has a system of communication, through which it formulates and implements its organizational goals and coordinates its diverse activities. Computer -mediated communication systems such as the intranet, increase the efficiency, speed and quality of data transmission, storage and retrieval of information and interactivity within an organization while overcoming the problems in communication associated with distance, time, and technical incompatibility (Newell, Scarbrough \& Swan, 2001). The intranet, unlike the Internet, which has open access architecture, consists of private networks offering features equivalent to the Internet, but is operated and maintained by companies and organizations for the exclusive use of its members and authorized users (Green, 2001).

Material published as part of this journal, either on-line or in print, is copyrighted by Informing Science. Permission to make digital or paper copy of part or all of these works for personal or classroom use is granted without fee provided that the copies are not made or distributed for profit or commercial advantage AND that copies 1) bear this notice in full and 2) give the full citation on the first page. It is permissible to abstract these works so long as credit is given. To copy in all other cases or to republish or to post on a server or to redistribute to lists requires specific permission from the publisher at Publisher@InformingScience.org
However, a technology is never neutral and can be used and implemented according to the wishes of the group or individuals in a position to make decisions regarding that technology based on their own interests, which can adversely affect the interests of others (Deetz, 1991). Therefore, criti- 
cal theorists consider it important to examine the various issues involved when an organization adopts a new communication technology or network that excludes some of its staff due to budgetary constraints or other reasons, and how it may adversely affect those staff's functions (Taylor \& Trujillo, 2001). The term 'critical' refers to challenging and exposing of actions or decisions one sees as unfair or inappropriate in a given situation (Eisenberg \& Goodall, 2001). Agreeing with this view, Jablin (1987) argues that an organizational structure or constraints that organizational members face in the communication process need to be highlighted, especially in relation to communication technologies. DeSanctis \& Fulk (1999) have suggested that it is essential to examine the unanticipated impacts that can result from managerial choices regarding technological implementation that directly affect the various stakeholders of an organization.

Manross \& Rice (1986) point out that when researching the adoption and diffusion of new technologies, it is important to study the failures as well as the successes. The current study is an example of the former. This is because, one needs to learn about the perceived attributes and benefits of an innovation as well as the political, technical and implementation processes that influence the success or failure of that innovation.

\section{The Case Site}

This paper reports on a case study carried out at an organization located in a rural Australian town of 12,000 inhabitants (referred to as the 'Town' hereafter), where the State Department of Human Services runs a residential care facility (or 'Center') with a capacity for 172 intellectually disabled persons (or 'clients') and employing 200 staff. This Center is the largest single employer of the Town, which is located $70 \mathrm{~km}$ away from the Regional Head Office of the Department, which handles all departmental policy matters relevant to this Center.

In early 1998, the Head Office decided to provide an intranet service to the Center as a means of improving communication between the Center and itself. The Head Office only carries out administrative functions and all its staff are provided with their own computer workstations networked to the intranet. But the Center in question consisting of nine different units and $200 \mathrm{em}-$ ployees who carry out diverse functions only had 20 computers, most of which were housed in its administration division. The administration unit and the six direct care units (which are residences for the clients and already had a computer each), were the only ones to be networked for the intranet. The non-direct care units (consisting of housekeeping, maintenance, stores, vocational therapy, physiotherapy and hydrotherapy units) were neither networked nor provided with computers. The computer that already existed in the catering division, which is a non-direct care unit, was excluded from the network. The limited implementation of the intranet facility was explained as due to budgetary constraints. It was also announced at the outset, that no additional computers would be networked or provided to the Centre due to the costs involved.

Once the intranet was installed, it became the only medium -via email and the Department's website, used by the Head Office to send memos and circulars, and provide procedural manuals and policy documents to the Center, previously sent or made available as printed materials. The direct care units had their networked computer located in the office of the Unit Manager, who was expected to print out the relevant memos and circulars received from the Head Office and post them on the staff notice board in the unit. The secretary to the Center based in the administration unit was expected to print out the emails and send them over to all non-direct care units for dissemination among their respective staff via their notice boards and memo folders thereafter.

But in reality, this did not always happen because the secretary in administration and the unit managers in direct care did not always attend to the proper dissemination of these emails received from the Head Office as envisaged. As a result, staff in both direct and non-direct care units often missed out on receiving important memos and circulars on time or at all. This was because the 
intranet had given rise to increased workloads for the secretary and the unit managers, due to the large number of email messages received via the intranet. Messages previously sent by telephone or passed on in person to the secretary even within the administrative division, were now sent as emails.

The intranet being provided only to the direct care units and administration also created a perception of non-direct care units being unimportant to the organization. This was in a climate where the Head Office had recently explored the feasibility of outsourcing of non-direct care functions at the Center and the state government at the time, which owned the Center was highly committed to economic rationalism, outsourcing and privatisation.

Even though being given access to the intranet was considered a status symbol within this organization for direct care Unit Managers by other staff, ironically, these Unit Managers, who are older nursing professionals of both sexes, did not feel inclined to use the intranet and delegated it to their younger Deputy Managers, who are also trained nursing professionals of both sexes. The Deputy Managers in turn complained that they were spending too much time on the intranet, which was taking them away from their first obligation, which is the hands-on care of clients. Other direct care staff became unhappy, because their Deputy Managers were now devoting less time to hands-on care, which increased other staff's workloads. These factors had led to low morale within the organization.

The Center also had very few social events that involved the entire organization, giving rise to an unhealthy organisational climate and lack of an organisational culture. The Center's newsletter meant for staff and clients' families had ceased publication a while ago, as the secretary in the administration who was responsible for it had been unable to find the time to work on it, even before the intranet was implemented. The Town's newspaper was also regularly publishing letters to the editor and news items, commonly believed to be instigated and sourced by the staff at the Center, that were negative towards the Center and its management. In response to all these factors, the Center's new Manager appointed a 'Communication Project Team' in August 1998 to examine the various aspects of organizational, interpersonal and mediated communication systems within the organization and to recommend suitable steps to improve its organizational communication, culture, climate, and image. The author served as advisor to this Team moderating the group's meetings and helping them to explore and report on suitable steps to remedy the problems caused by the intranet and other modes of communication within the organization.

This paper reports the findings of the author who examined the problems related to the effects of the Center's limited adoption of the intranet, implemented at the sole discretion of the Head Office without seeking the input or feedback from the staff of the Center, at any time before, during or after implementation.

The rationale for this case study is that, computer-based (communication) networks (CBN) are driven by human intentions and are implemented by those with the power to make decisions, based on their wishes and agendas (Davies and Harvey, 1994). Therefore, analyzing the implementation of a CBN makes the power and effects of such networks on the less powerful more visible and makes those responsible for the decisions about their implementation socially more accountable. Therefore, as Taylor and Trujillo (2001) have argued, it becomes useful to adopt the critical approach when critiquing an organization or examining an aspect of its organizational reality.

\section{Adopting New Communication Technologies}

Information technologies in general and computer-based networks (CBNs) in particular, are means of producing and manipulating knowledge-objects (Davies \& Harvey, 1994). Michel Fou- 
cault conceptualized knowledge-objects as creations and products of political domains (Foucault, 1974). This creates "a political context where some (individuals and groups) will benefit due to their ability to interact in a particular knowledge paradigm while others will be victimized due to their inabilities" (Davies \& Harvey, 1994, p. 137).

Decisions regarding the adoption of a new technology within an organization represent different group and individual interests. Therefore, new technologies could end up supporting existing power configurations and sustain current differences between groups instead of changing them (Deetz, 1991). This can result due to budgetary constraints where a new technology is allocated only to the already privileged or powerful within an organization, which leads to the exclusion and further marginalization of the powerless. Power and resource equalities / inequalities between participant organizations can lead to the more powerful organization forcing the less powerful one to adopt a given technology as well as decide which system to adopt (Andriessen, 1994).

As communication is central to all structures and actions of organizations, the task of the critical theorist is to discern the factors that negatively affect the process of communication (Alvesson \& Willmott, 1992, p. 14; Deetz, 2001). The goal of critical theory is to help organizational members develop ideas and practices that will remove existing unfair barriers to communication (Taylor \& Trujillo, 2001). As the power of different participants within an organization is based on conditions of resource control and resource interdependence (Pfeffer, 1981, p.184; cited in Mumby, 2001), it is useful to examine how resource allocation with respect to communication technologies creates barriers to communication (Newell, Scarbrough \& Swan, 2001).

\section{The Optimistic, Pessimistic and Pluralist Views of New Technologies}

The individual and social impact of office automation or any other new communication technologies can be described under three broad positions, namely the optimistic, pessimistic and pluralist views (Hirschheim, 1985). The optimistic view takes the utopian view of technology, which sees new technology as improving efficiency, productivity and communication within an organization and leading to social equality (McLuhan, 1969) by bridging the gap between the 'haves' and the 'have-nots'. The pessimistic view suggests that technologies are used to extend the power and control of management or other power holders (Beniger, 1986). For example, Olsen \& Lucas (1982) argue that most computer technologies applied to office automation and procedures are not aimed at improving efficiency but to change the nature of office work altogether. The pluralist view on the other hand, considers technology as apolitical like a building block, which is neutral in it self, but which as a structure, reflects the desires and wishes of the designers or controllers of the system (Burns, 1981). This view positions technologies as creating possibilities, which are either positive or negative depending on the way they are put to use (Hirschheim, 1985). Therefore, understanding the values and beliefs of the management of an organization in implementing a given technology, makes possible the exploration of the potential implications of adopting or implementing it.

The Justification Model of Technology (Hamelink, 1988) argues that technology adoption is a form of 'social gambling' as no one can accurately predict what a technology can do as we only have partial knowledge of its capabilities and uses. Once adopted, we also cannot predict or envisage how and for what it will be used and most of all, what its overall effects will be.

According to Kohler (1994), "The basic decisions in the design of any computer conferencing application (such as the intranet) are determined not by the computer system but by the dominating organizational concepts" (p. 226). If this is done without knowledge about organizational development, it may result in non-acceptance (of the technology), negative reactions and even genuine conflicts' (Kohler, 1994, p. 226). "The investment in the new technology will only be effec- 
tive if management fully understands the needs of the "diverse community of users" (Schneiderman, 1989, p. 169 cited in Morley, 1994, p. 323) of that technology.

\section{Computer Mediated Organizational Communication}

The adoption and utilization of computer mediated communication in organizational settings has been commonplace and established in workplaces of Australia and other developed countries since the early 1980s and the intranet since the early 1990s (Bernard, 1998), even though the Center under study had the intranet system adopted for its limited use only in early 1998. As a result, most existing literature on the impact of the adoption of computer-mediated communication was published in the 1980s and the early 1990s. This includes studies related to the acceptance of computer mediated communication systems (Andreissen, 1994; Dewhirst, 1970-71; Kerr \& Hiltz, 1982; Manross \& Rice, 1986; Rice \& Shook, 1988; Steinfield, 1990); office automation from a social and an organisational perspective (Andriessen \& Roe, 1994; Hirschheim, 1985; Kohler, 1994; Morley, 1994; Olsen \& Lucas, 1982; Peiro \& Prieto, 1994; Sypher, Sypher, Housel, \& Booth, 1990); and computer system usage and outcomes (Rice, Hughes \& Love, 1989; Rice \& Steinfield,1994; Romm, 1999; Ruchinskas, Svenning, \& Steinfield, 1990). Technological reasoning and decision-making (Deetz, 1985; Habermas, 1972), media appropriateness (Rice, 1993) and the uses and gratifications of adopting computer-mediated communication (Perse \& Courtright, 1993) are other lines of inquiry into computer-mediated organizational communication.

\section{Adoption of New Technologies}

Rogers (1983) sees the adoption process of a new electronic communication system as dependent on environmental conditions, characteristics of the innovation and organisational conditions. Confirming Hamelink's (1988) theory of technology adoption as a gamble, Newell, Scarbrough and Swan (2001) in a study of the intranet adopted at a large global bank found that it created 'electronic fences' by reinforcing demarcations between existing national and functional boundaries and encouraged fission, instead of integrating individuals across the organization as intended. This was because the intranet could enable as well as disable processes of communication, collaboration, social co-ordination, and reinforce divisions across groups within organizations. Fulk and DeSanctis (1995) indicate that the adoption of information technology is closely liked to organizational structures and routines such as pre-existing relationships and the distribution of resources, which influence the design, development and use of technology.

Poole (1999) points out that technologies are not necessarily used for control and domination as the pessimistic view of technology sees it, but that values of the existing power structure that are embedded in the decisions made with respect to a technology, could affect the use and implementation of that technology. This may be the reason why the adoption of a given technology can result in unexpected outcomes (Orlikowski, 1992). Accordingly, viewing information technology (IT) simply as a means of improving efficiency as argued by the optimistic view of technology, overlooks the other effects of technologies, employee relations, work practices, and values (Deetz, Tracy \& Simpson, 2000).

The nature of an organization's IT use arises through complex interactions between the intentions of key actors, attributes of the technology itself, and the organizational dynamics. As the pluralist view suggests, if used well, the technology can be of great benefit to an organization, while used inappropriately it could lead to negative consequences (Zmud, 1989). Johansen and De Grasse (1992) in their study of computer-based teleconferencing and its effects on work patterns found evidence supporting the pessimistic view (Hirschheim, 1985) that computer-based networks can be used as a means of controlling, dis-empowering and manipulating those who have no access to the technology, by excluding them from communication exchanges, because a strong relationship 
exists between communication, power and organizations (Mumby, 2001). Romm (1999) has shown how email can be effectively used by staff, to coordinate intra as well as inter organizational activities, across space and time zones.

Most formal organizations are hierarchies, where managers make the decisions about the implementation of new technologies used by subordinates. Under the presumption of improving efficiency, the managers will allocate responsibilities and authority as well as perquisites, power, and positions to the subordinates. This chain of domination leads to elements of pleasure or pain to the individuals who are part of the system (Goodman Griffith, \& Fenner, 1990).

\section{Effects of Adopting of New Communication Technologies in Or- ganizations}

The adoption, use and consequences of new communication technologies within an organization are influenced by a range of individual, group and organizational factors. These factors include task requirements, the characteristics of the work context, and the social dynamics of the potential users. The constraints placed on the user such as access to the medium (eg. the availability of computer terminals) and the ease of transforming the message from one medium to another and/or from the original sender to the ultimate receiver via the gatekeeper (eg. from email message from Head Office to printed messages on the staff notice board at the Center), also influence the effectiveness of the communication process (Rice \& Steinfield, 1994).

Technologies perceived by managers and users as increasing the control or the stability of the systems under their control, are more often adopted than the ones that are not (Bariff \& Galbraith, 1978; Bjorn-Andersen \& Pedersen, 1980). Decision-makers that want a particular technology adopted, generally argue that it will improve on the old ways of doing things. But in reality, it helps the status quo to remain intact or even be strengthened in the process (Goodman et al., 1990), which supports the pessimistic view.

The 'Coalitional Model of Power' (Pfeffer \& Salancik, 1974, cited in Mumby, 2001) argues that in terms of resource allocation, organizational decision-making becomes a political process linked to the current power structure of the different sub-units within an organization. But any organizational medium, be it meetings or memos, has the potential to structure the access to resources such as information-either intentionally or otherwise (Rice \& Gattiker, 2001).

Changes brought about in organizations due to adopting a new technology can give rise to 'techno-stress' and 'techno- trauma' caused by fear and anxiety about changes to their work and jobs leading to psychological and physiological problems affecting employee health and well being. But it could also have the positive effects of enhanced autonomy, increased status, higher productivity and decreased boredom and tedium. Therefore, management needs to communicate and explain these changes to staff in order to gain their support for the innovation (Sypher et al., 1990). The organization also needs to examine the different information needs of various types of employees and work units and urgently respond to these needs while keeping the staff informed of any changes envisaged and how they would affect their work lives via formal communication channels (Sypher et al., 1990) such as a newsletter or training sessions. In other words, successful implementation of a technological innovation needs employee participation and communication in a timely manner. It is also quite common for a new technology to be accompanied by 'bugs' which need to be debugged' with user feedback (Ruchinskas et al., 1990). The users also need to be reassured that such problems are natural and not their fault. 


\section{Using email in Organizations}

Managers and professional staff in organizations spend a good part of their workday in communication via face-to-face interactions and the telephone. The use of email helps them to reduce and structure their time used that way due to email being asynchronous and able to reach a large number of receivers with just one message (Steinfield, 1990). However, email is low in social presence and is less personal due to the absence of non verbal cues (Ruben \& Stewart, 1998) and therefore less suitable when the information transmitted is ambiguous or subject to multiple interpretations and as a result, is more suitable for more routine and simple exchanges. Most users consider email as improving productivity, accessibility and quality of work units (Steinfield, 1990).

\section{Gatekeeping and New Communication Technologies}

The limited availability of a new technology only to some segments of staff due to high costs of providing the facility to all employees or the complexity of the technology, inhibit rather than facilitate strategic information behaviors (Zmud, 1989). As a result, information transmitted via this technology will have to reach the others through an intermediary, such as a secretary or manager who has access to the technology. This will result in that individual unwittingly becoming a 'gatekeeper' (Pettigrew, 1972) to the information in question. A gatekeeper is the person who sits at the junction of communication channels and is in a position to open, close or regulate the flow of information (Pettigrew, 1972). The new technology also drastically increases the number of messages to be received and processed by that intermediary and increases his or her workload (Zmud, 1989).

\section{Factors Affecting the Use of a New Technology}

The functionality of the technology and the manifest rewards of using it (such as learning new skills, less fatigue), and latent rewards (such as recognition and status conferral) also have important consequences for the utilization of a given technology (Goodman et al., 1990). Computerbased communication increases a staff member's status relative to peers without access to it (Kerr \& Hiltz, 1982). Therefore lower status staff are more enthusiastic about being seen working with computers to enhance their visibility and perceived status. People over 55 years of age may be less inclined to use a new technology due to their lack of familiarity with it or their general reluctance to accept changes in their basic communication patterns, even with proper training to use the new technology (Kerr \& Hiltz, 1982).

Some staff may refuse to or claim to dislike a new technology citing various reasons simply to cover up their lack of skills or training to use it as a 'face-saving strategy' Goffman (1967). Since a new technology is first used to replicate the functions carried out by the existing or "old" technologies (Stephens, 1998) referred to as the 'established base' (Green, 2001), such as email replacing telephone calls or printed memos, individuals who are reluctant to use a new technology for whatever reason may be able to justify their decision not to adopt it, at least initially. However, the most common reasons given by users to explain their limited use of a new computermediated communication system are information overload and that other 'off line' activities must take higher priority (Kerr \& Hiltz, 1982).

Manross and Rice (1986) argue that an innovation must provide a benefit to the individual usernot just to the organization if it is to be successfully adopted, because innovative use is not enough reason for users to adopt it in their day-to-day work. Therefore, there must be some aspect of the technology that is specifically attractive or useful to the potential adopters. As a result, 
needs of the individual and the organisational adoption need to be managed and examined differently.

\section{Method}

This study used the methodology of a case study to examine the phenomenon discussed in this paper. Simply put, a case study is an empirical inquiry that uses multiple sources of data to investigate a contemporary phenomenon or problem within its real life context, when the boundaries between the phenomenon and the context are not very clear (Yin, 1994 cited in Wimmer \& Dominic, 2003). Case studies however, provide a better understanding when used in combination with theory. Deetz (1990) recommends case studies as 'one of the best ways to overcome the misleading separation of theory and practice and to provide skills in conception and judgement' ( $\mathrm{p}$. viii). Using more than one method of data collection such as direct interviews, direct observations and focus groups etc. also increases the validity of the findings of a case study (Wimmer \& Dominic, 2003).

\section{Research Questions}

Using the qualitative data (Taylor \& Trujillo, 2001) collected from five methods of data collection and various sources, and taking the inductive approach, the following research questions were examined (Stake, 2000).

1. What are the issues related to gatekeeping within this organization that negatively affected the proper dissemination of email messages received from the Head Office to staff without direct access to a networked computer?

2. Did the limited adoption of the intranet help maintain and reinforce the privileged position of some units and staff within this organization?

The author conducted this case study by leading the discussions of the 12 -member 'Communication Project Team' ('Team') at the Center. These discussions were held on three occasions. The 'Team' consisted of three administrative, three direct care (nursing) and four non-direct care staff members from various levels of the organization's hierarchy and represented various age groups from both sexes. The Information Technology (IT) Manager at the Head Office attended the first two of these meetings and the Convenor of the 'Team' attended the meetings as note taker to help the author who served as the moderator of the group discussions and to record the minutes of the meetings. These discussions can be categorized as informal focus groups (Morgan, 1997).

At the outset of the project, the author decided not to tape record the meetings of the Team as a means of gaining the trust of its diverse group of members and to make them feel free to express their opinions. This was due to the existing organizational climate where the Center's staff appeared to distrust the Head Office and feel insecure of their future. The author and the convenor took detailed notes on the discussions and soon after the meetings, the author would write down as many of the relevant verbatim quotes from the members as possible, based on the author's and the Convenor's memory. These quotes therefore, are factually accurate in terms of the opinions expressed by the various members of the Team, even though they may not always be verbatim. Wimmer and Dominic (2003, p. 121) accept this method of recording focus group proceedings as valid where the moderator writes brief synopses of what was said and offers interpretations of the subjects' responses.

The data thus collected was analysed by the author by examining discussions of the Team as related to all modes of communication within the Center, under the various themes such as print media (newsletters, brochures etc.), telephones (landlines, pagers and mobiles), public address 
systems (public announcements made from the administration unit to other units), emergency alarms, the intranet and interpersonal communication (meetings, performance evaluations, counselling sessions, social events or lack thereof ). This paper only discusses the findings as related to the intranet.

As the second method of data collection, the author informally interviewed three females and three males selected from the staff at the Center, based on their availability, resulting in a convenience sample (Wimmer \& Dominick, 2003). They represented various units and answered the author's questions about their experiences and views on the limited adoption of the intranet at the Center (McCracken, 1988). Here too, the discussions were not tape recorded as a means of gaining the trust of the subjects but were written down by the author in as much details as possible during the discussions and immediately afterwards. This method too is acceptable in carrying out depth interviews as a research methodology where personal interviews at a subject's workplace can be conducted via semi-structured interviews and the data collected by writing down their answers to researcher's questions (Wimmer \& Dominic, 2003, p. 182).

The third method of data collection was via examining all intranet messages sent by the Head office to each unit that was networked, for a randomly selected two-week period. These messages were then compared with the emails of memos received by the Center, and then had been printed and sent by the secretary in administration to the non-direct care units and staff who had no access to the network, during the same two-week period. This qualifies as an unobtrusive study similar to those discussed in Ward and Hansen (1987) and Rice, Hughes and Love (1989). This process examined the discrepancies between the emailed memos sent from the Head Office and received by those units with and without direct access to the intranet. It should be noted that the intranet is used only for official purposes at the Center and therefore no personal messages were among those examined during the two-week period under study. As a result, this method of data collection did not involve any issues of privacy (Punch, 1986).

As the fourth method of data collection, the author consulted with the convenor of the 'Communication Project Team'- a senior administrative manager and a long-term staff member of the Center with a nursing background, who served as the 'informant' (Johnson, 1990) within the organizational setting. He answered the questions posed by the author about the history and background of the Center throughout the research process and clarified any issues that were unclear to the author.

As the fifth method of data collection, the author physically observed the facility's layout (Adler \& Adler, 1987) regarding the location of the various units, their networked computers, and the notice boards on which the printed intranet messages were to be displayed for access by staff as another unobtrusive study (Rice, Hughes and Love, 1989; Ward \& Hansen, 1987). This was to gain an understanding of the accessibility of the memos sent from the Head Office as emails to direct care units to staff who were neither the Unit Manager nor Deputy Manager and therefore could not personally access the intranet as the computer was located in the Unit Manager's office. It also helped the author to examine the distance between the computer on which the intranet was accessed and the staff notice boards on which these messages had to be posted after printing, to gauge the organisational structures (Rice \& Gattiker, 2001) or physical constraints that may restrict the proper dissemination of the emails to direct care staff without access to the intranet, due to the inconvenience faced by the Unit Manager and Deputy Manager, if the computer and the notice board were not located close of each other.

Using more than one method of inquiry (physical observation, informal focus groups, interviews with staff, use of an informant and examining intranet messages) was an application of methodological triangulation (Wimmer \& Dominick, 2003) in this research project, which provides a more comprehensive view of the problem under investigation. 


\section{Findings}

By analysing the data collected, each research question was examined and then discussed as to their implications to the organization and its members, in order to examine how the limited adoption of the intranet and the resulting communication practices introduced by the Head Office had affected the Center and its staff.

RQ 1: What are the issues related to gatekeeping within this organization that negatively affected the proper dissemination of email messages received from the Head Office to staff without direct access to a networked computer?

\section{Effects of the Limited Adoption}

The main problem caused by the intranet as a channel of communication was that it was not available to all units and the units that did were limited to just one computer accessible to only two staff members (the Unit Manager and Deputy Manager) of the unit. The Team discussions indicated that having just one networked computer in each unit was inadequate.

Annie- a junior level female direct care employee in her mid fifties informed the author that she is willing to learn and use the intranet. "If they give me a computer and show me how to do it (sic)... I will use it." John, a carpenter in his late fifties and attached to housekeeping - a nondirect care unit, mentioned that "I took this computer course in town last year....So I know how do use email..." This indicates that unlike the direct care unit managers of the same age group who refuse to or are reluctant to use the email, these less educated staff are eager and willing to use it, but currently have no access to it.

The examination of all intranet messages received from the Head Office and the printed intranet memos sent by the secretary in administration to non-direct care units indicated that several important memos were not received by the non-direct care units during the two-week period under study. These included memos related to job vacancies, reports, enterprise bargaining updates, announcement of workshops, and salary packaging, which are important to all staff for their professional development and welfare.

Narelle- A female direct care Unit Manager in her fifties told the author that she does not use the email because "It is so impersonal.., I prefer to use the telephone." During the team discussions it was pointed out that the Head Office only provided one training session for staff expected to use the intranet and that some staff (Managers and Deputy Managers in direct care) had missed it, due to being on leave at the time. According to the informant, Narelle, who refused to use the intranet on the grounds of it being impersonal, had been one of them. This indicates why at least some Unit Managers avoid the intranet and delegate it to their Deputies.

The Head Office had claimed that the costs of networking the non-direct care units, obtaining additional computers, and providing the training required by all staff to handle the intranet were prohibitive. During the first meeting of the Team, the IT Manager from the Head Office said, "We can't provide any more computers or the intranet to (the Centre).... It will cost about $\$ 100,000 \ldots$ The money is not there...."

\section{Factors Causing the Failure of the Intranet}

There were several factors that had caused or resulted in staff in non-direct care as well as direct care to not receive email messages sent from the Head Office. These included issues related to gatekeeping, organizational structures and the nature of work at this organization. 


\section{Gatekeeping}

The examination of the intranet messages for the two week period under study confirmed Pettigrew's (1972) findings, because the direct care Unit Managers, Deputy Managers and the secretary in administration, had unwittingly become 'gatekeepers' of information that were useful to other staff in the organization when they were became responsible for disseminating the emails received from the Head Office to other staff. As Zmud (1989) had pointed out, the intranet had added to the workloads of these gatekeepers. For example, the informant explained, "Before the intranet, I would get about 4-5 letters a week directly addressed to me.... Now with the intranet, I get about 160 email messages a week."

However, no provisions had been made by the organization to provide the Secretary in Administration with any extra help to accommodate this increase in her workload, such as help with photocopying of emails to be sent to each building housing the various non-direct care units or for Deputy Managers in direct care who are handling the email, to be relieved of some of their normal duties which could be carried out by an extra worker to accommodate the additional workload caused by the intranet.

By failing to provide any additional training sessions to Unit Managers who are expected to use the intranet, but had missed the training when it was offered, this situation remains unchanged and the problem unsolved as they cannot be persuaded or expected to use it in the foreseeable future.

\section{Organizational Structures}

Confirming Rice and Gattiker (2001), the location or physical structure of the networked computer in the unit Manager's or Deputy Manager's office, constrained other staff from using the computer or the intranet, even if they were willing (Annie) or had the skills (John) to use it, making the role of gatekeeper even more relevant at this Center. Here, knowledge and skills related to the intranet of those staff without access to the technology were proven worthless. Due to the confidential nature of the information and data about the clients stored in the Unit Managers' computers, it is also not advisable to allow free access to them by all staff or have them placed in unsecured locations within the unit.

The author observed that the physical layout of the various units within the organization was also a factor contributing to the problems with the dissemination of email by the main gatekeeper - the secretary in administration. Established in 1976, the Center had been originally designed to house 30-40 residential care units. Therefore the original seven residences (one has been closed down since) and the non-direct care units were built about 200 meters apart from each other on uneven terrain on a block of land of about 50 acres. The non-direct care units are located far away from each other as well as from the administration building located in the middle of the complex. The distance between various units was such that after the Communication Project Team meetings held in the administration building, some staff would seek a ride from the author to be driven back to their own units to save time.

This means the secretary in administration had not only to print out the emails received from the Head Office but make several copies of each and have them sent over to the many buildings housing the various sections of the three non-direct care units at different locations, within the Center via the internal mail.

The author noticed that in the direct care units, the staff notice boards were not always located in close proximity to where the computer was, which may have served as a inconvenience to the Deputy Managers when posting the messages on the notice boards. These served as the organiza- 
tional structures (Jablin, 1987; Rice \& Gattiker, 2001) that constrained the gatekeepers in the proper dissemination of the emails to other staff.

\section{Nature of Work}

The nature of the work within this organization was also a factor that negatively affected the proper distribution of emails received from the Head Office to staff, by interfering with the work routines and schedules of the gatekeepers. Due to the Center being a residential care facility for the intellectually disabled, the clients need round the clock care and include some clients with difficult, challenging, and unpredictable behaviors common to the intellectually disabled, which makes it difficult for the Deputy Mangers to structure their time and stick to a time table as planned. According to the informant, these clients can create unforeseen situations or 'incidents' that require their immediate attention and time to carry out the additional administrative and other duties related to them. "Some clients have their own routines.... They have to do things exactly the same way, at the same time every day.... So suddenly a new causal worker comes in.... he or she doesn't know about this routine.... So they will do something a little different... This can make the client very upset and he or she can create a big scene....So the Unit Manager or Deputy Manager has to stop everything else and look into this...."

In recent times, the procedures and administrative paperwork involved in reporting such incidents have become more complex and extensive due to legal and other requirements. Such off-line work can make the gatekeepers lag behind in their routine jobs including the dissemination of emails received from the Head Office to other direct care staff (Kerr \& Hiltz, 1982) because incident reports need to be filed immediately and the resident or client involved in the incident calmed down.

\section{The Main Problem}

The main problem with the process of disseminating messages from the Head Office to Center staff without access to the intranet was that instead of being a one-to- many or many-to-many medium as the intranet essentially is, it was effectively adopted between the Head Office and the Center as a few-to-few medium (Rice \& Steinfield, 1994), which excluded most staff at the Center, who then had to depend on the gatekeepers to receive the information necessary for them to carry out their jobs effectively and efficiently.

\section{Team Recommendations}

Based on the author's research findings, the Communication Project Team recommended that a second networked computer in each direct care unit and a networked computer in each non-direct care unit be provided at the Center and that they be located in a common location accessible to all staff in a unit. All staff was also to be provided with training in using the intranet. This would relieve the secretary in administration and the Unit Managers / Deputy Managers of their gatekeeping roles.

The Team also suggested a common room for staff to be established, as there appeared to be a lack of personal interactions between staff from direct and non-direct care units within the Centre. It was recommended that a networked computer and printer be provided for this room so that staff could use it to access the intranet during their breaks.

The author felt that the existing situation of limited implementation of the intranet, when it was the main means of communication between the Center and the Head office, was unfair to staff in non-direct care and affected the participation of organizational members through computer and 
information systems (Mantovani, 1994, cited in Rice \& Gattiker, 2001). One could also claim that this situation created a 'digital divide' within the organization.

RQ 2: Did the limited adoption of the intranet help maintain and reinforce the privileged position of some units and staff within this organization?

\section{Economic Rationalization and Limited Adoption}

When economic considerations overrode those of the non-direct care units and their staff when the Head Office was implementing the intranet in a limited manner, the technology reduced the scope for debates about political and ethical issues related to adopting a new communication technology (such as the fairness of excluding some staff from the adoption and use of new technology and the inconveniences they may face as a result) (Alvesson \& Willmott, 1992). It thereby helped preserve the status quo in favour of the direct care units considered more important to the Center than the non-direct care units, whose services may be outsourced if necessary. Generally, a limited resource is first allocated to those perceived as more important to or privileged within an organization.

When the Head Office unilaterally decided to network the Center, provide the network only to the administration and the direct-care units and then decided that thereafter all memos from them would be sent via the intranet, it exercised its power over the small rural Center, which was faced with an uncertain future. The Head Office also had not considered it necessary to conduct followup training or seek feedback from the users about any problems with the intranet and its limited implementation.

Even though one cannot imply any malice or indifference on the part of the Head Office towards the Center, one can argue that the intranet adoption could have been better handled and thought out by paying attention to the realities of this rural organization. With rumors ripe about the possible outsourcing of non-direct care functions, those staff could have interpreted their exclusion from the intranet as further evidence of their marginalized status and job insecurity.

When the author interviewed Cathy- the Unit Manager of one of the non-direct care units, about the intranet, her sad and hurt reply was "Oh, we are not important enough to be get email (sic) (the intranet system)... They forget to send me the memos that are important to me and my staff... This happens all the time....." In her opinion, the intranet had conferred status on those units and individuals given access to it. Even though she was equal in rank to managers in direct care, her position as a non-direct care professional had reduced her status in relation to the nursing professionals that manage the direct care units. As health care professionals, direct care staff who are higher qualified academically and professionally, earn more than non-direct care staff who are in trades or less likely have completed their tertiary education. The new technology of the intranet being given only to direct care staff therefore reinforced this asymmetry in their status.

The Head Office unilaterally deciding on adopting the intranet for others based on their own agendas and convenience indicated their power while the direct care Managers and Deputy Managers at the Center with the intranet became further privileged, due to having access to information, unlike their non-direct care counterparts.

\section{Patterns of Decision-Making by the Head Office}

The installation of a video conferencing system at the Center soon after the intranet was implemented is another example of the exercise of power by the Head Office according to its own wishes. The informant observed that, "They only set it up because they don't want to travel down 
here for meetings". The Head Office which used cost as an excuse for limiting the intranet training beyond the initial familiarization, had spent $\mathrm{A} \$ 32,000$ on this video conferencing system, that was rarely used. Its existence was not known to the staff working outside the administration building including the three Communication Project Team members who were trade union officials, until it was announced at the Team's first meeting by the IT manager from the Head Office. This indicated the lack of downward communication at the Center as the system by then had been in existence for two months and was yet to be used. It was used for the first time for the second meeting of the Communication Project Team to link the IT Manager from the Head Office- four months after installation.

The IT Manager explained that, "With this (the video conferencing) system, people don't have to travel down the highway for meetings." In other words, it saves 'trash travel' (Ruchinskas et al., 1990), for the Head Office staff, which increases their productivity, which undoubtedly is a positive outcome. The Manager of the Center in an informal discussion with the author mentioned that there was a very small branch administered by the same Department based six hours away from the Head Office. "....This branch should have got the video conferencing system....Those poor guys travel for hours to get to the Head Office for meetings. They don't have intranet or even a voice point (for audio conferencing)...." He argued that the decision was simply made for the convenience of the Head Office staff.

Therefore, I would argue that as Deetz (1991) points out, the choice of new technologies used in organizations is carried out in identifiable patterns, such as for the convenience of the Head Office, rather than randomly. As many researchers such as Robey (1981), have concluded, the limited implementation of the intranet at this Center had reinforced the status quo in terms of a particular function (of the system of the Head Office sending information to the Center). The main influence was not technical, but implementation and operational strategies imposed by the power elites at the Head Office (Rice \& Gattiker, 2001), which agrees with the pluralist view of technology (Hirschheim, 1985).

The Convenor of the Communication Project Team and the Center's Manager both advocate providing the intranet to all units but so far had been unable to influence the Head Office to provide the necessary funds. The Convenor mentioned that he tried to do so because "It is not efficient.., All units must have computers and the intranet. But the Head Office won't listen..." He empathized with the staff without access to the intranet, as he remembered how sad he felt recently when the administrative staff, were given new computers after several years of using the existing ones, while he was not, because his was only 12 months old. "Now that you mentioned it...., I remember how I felt when I was the only one in the building who didn't get a new computer.... I walked around looking at other people's computers..., feeling sad....jealous... feeling sorry for myself....This is when I already had a decent computer... So I know how the non-direct care people must be feeling..."

Therefore, I would argue that providing a new technology only to one group, results in others feeling marginalized, excluded or disadvantaged and therefore is an unethical and unfair practice that should be avoided, when implementing a new technology within an organizational setting.

\section{Member Involvement in Finding Solutions}

During one group interview, John also provided many suggestions for cutting the cost of future networking of the non-direct care units by pointing out that most work can be performed inhouse. "Nick (referring to the IT Manager)...We can network the non-direct care units in-house. It won't cost anything... We only need the computers and the software (from the Head Office)." This is another situation where knowledge of staff members such as John- who are not part of the decision-making group and had no access to the technology, had not been utilized when deciding 
that any further networking of units was not feasible. However, to his credit, the IT manager who at the first meeting of the Communication Project Team had directly stated that further networking was not possible due to the costs involved, willingly accepted John's suggestions and agreed to incorporate them in his recommendations and future decisions about the intranet at the Center.

\section{New Technology- Same Old Functions}

Throughout history, new forms of communication technologies have initially been used to imitate older forms of communication such as print replacing the same functions and forms of hand writing (Stephens, 1998) or video conferencing being used for meetings previously conducted faceto-face (Fulk \& Collins-Jarvis, 2001). Reinforcing this view, the examination of the intranet messages for the selected two weeks indicated that some emails sent within the Center were information about telephone messages left for a particular staff member, such as "Steve, Mrs. Mary Williams called, Tel. 555- 2315".

In other words, the e-mail imitated the handwritten message slip carrying details of a caller's name, phone number and a brief message taken by a colleague, the secretary, or the voice mail that is automatically activated. The intranet is used by the Head Office to send memos and circulars previously sent as printed messages. The Department's website carries information about new procedures, which were previously available as printed manuals. In other words, the intranet has not been used so far for a completely new function of communication within this organization, but was still replicating the functions carried out by the older technologies or the established base (Green, 2001) of print and telephone.

This allows Unit Managers such as Jenny to avoid using the intranet, as the old technologies such as the telephone are more than capable of serving her current communication needs.

\section{Conclusion}

According to critical theory, participant organizations in a communication network can be either equal or unequal in their power and resources (Andriessen, 1994). Most often they are unequal and the more powerful such as the Head office, can force a system on the less powerful participant or the Center and decide whether to adopt or which system to adopt. The powerful in this situation had also decided who gets it and for what purposes, which was in the powerful partner's interests and convenience. They also had not sought the views, input or feedback from the Centre staff at any stage of implementation. Such a top-down management practice can create resentment and feelings of powerlessness within organisational members, who like Jenny and the other Unit Managers, may not be willing to try out a system initially as they have no sense of ownership of the new technology or policy, even if the system is useful for them and more efficient for the purposes it was implemented for.

As the pluralist view of technology (Hirschheim, 1985) suggests, the intranet as well as the video conferencing system adopted at the Center reflected a pattern of decision-making that was based on the desires of the controllers of the system, and the intranet created negative repercussions for the staff, even though the technology per se was neutral (Deetz, 1991). It also helped maintain the status quo in favour of the more privileged direct care staff and further marginalized the nondirect care ones. This shows that a computer-based network has the potential as a socio-political tool of domination (Beniger, 1986) and for creating problems within an organization.

The reason a new communication technology adopted in an organization causes negative effects is that its design and /or implementation fails to consider the demands and expectations of the users. It could also be due to such services failing to 'facilitate the development and maintenance of optimal formal and informal communication structures' such as networks, channels and roles. 
A communication structure is a result of an organization's structure and informational needs (Christie, 1995, p. 35 cited in Piero \& Prieto, 1994).

Bernard (1998) points out that many intranets are constrained by the old assumption that computer networks are to be restricted and rationed for use, even though they are first and foremost conduits for communication and collaboration and should be a tool for everyone. He argues that unless 'set free,' an intranet cannot 'grow and thrive.' In other words, as Steinfield (1990) argues, "Why have a system that only a few employees use?" (p. 239). Bernard (1998) sees the intranet as most useful when used for communication between workgroups, which are separated by distance, but only when levels of employee access to computers is high or there is a dedicated terminal located in an easily accessible area. In addition, staff should be provided with the necessary basic training to use the technology.

The Head Office was right with reference to linking organizational units and work groups separated by geographic distance, both between the Head Office and the Center and between the direct care units and the Center's administration. But they got it wrong with reference to adequate access to terminals and training of all staff to use the technology.

Then main problem with the implementation of the intranet at the Center was that the Head Office did not examine or envisage the social impacts of the adoption of this technology. In other words, it did not focus on the employees or be sensitive to or conscious of how the changes will affect their work.

At any stage of the implementation, the use of email for communication between the Head Office and the Center was also not an optional one among many others for staff, and the Center. The Head Office also had not conducted any trials with potential users to examine how it will be useful or what problems they will face in the process. In other words, the users were not given a chance to experiment and provide feedback on teething problems that could have been fixed before the intranet was made compulsory.

According to Romm (1999), when implementing a network, an organization needs to be well examined as to the potential social and other effects on power distributions and policies in the organization-such as who stands to gain or lose as a result of the implementation.

\section{Alternative Explanations}

Eisenberg and Goodall (2001) see 'creativity' of an organisational member as 'getting what one wants within the constraints of the organization'. Therefore, one can wonder of Jenny and other Unit Managers are doing just that when avoiding the use of the intranet, which was imposed on them from the Head Office, by getting their deputies to handle it.

Unit managers could have also resisted the implementation of the intranet that burdened them and see it as dealing with mundane issues and a waste of time, better handled by someone else while they spent their time in 'real' management. Their refusal to use it could also be 'passive resistance' to a top-down management decision made by the Head Office, without any input for feedback from them- the users of the innovation.

\section{Epilogue}

Soon after the Communication Project Team submitted its recommendations to the new Manager of the Center, there was a change of State government (which owned the Center) and within three months of the submission, the Center had received an additional networked computer and a printer in each direct care unit, a networked computer and a printer in each non-direct care unit and all of them were located in areas accessible to all staff within the relevant units. The existing 
Occupational Health and Safety $(\mathrm{OH} \& \mathrm{~S})$ room located in the administrative division had been modified to serve as a common staff room, the lack of which had been a shortcoming of this Center. This room was provided with a networked computer and printer for staff to use during their breaks. All staff were also provided with the necessary training to use the intranet.

\section{References}

Adler, P. A. \& Adler, P. (1987). Membership roles in field research. Newbury Park, CA: Sage.

Alvesson, M. \& Willmott, H. (1992). Critical theory and management studies: An introduction. In M. Alvesson and H. Willmott (Eds.), Critical management studies (pp. 1-20). London: Sage.

Andriessen, J. H. E. (1994). Conditions for successful adoption and implementation of telematics in userorganizations. In J. H. E. Andriessen and R. A. Roe (Eds.), Telematics and work (pp. 411-439). Hillsdale, NJ: Lawrence Erlbaum Associates.

Andriessen, J. H. \& Roe, R. A. (1994) (Eds.). Telematics and work (pp. viii-x). Hillsdale, NJ: Lawrence Erlbaum Associates.

Bariff, M. L. \& Galbraith, J. R. (1978). Interorganizational power considerations for designing information systems. Accounting, Organizations and Society, 3, 15-27.

Beniger, J. R. (1986). The control revolution: Technological and economic origins of the information society. Cambridge, MA: Harvard University Press.

Bernard, R. (1998). The corporate intranet: Harness the power of the next generation intranet $\left(2^{\text {nd }}\right.$ ed.). New York: John Wiley \& Sons.

Bjorn-Andersen, N. \& Pedersen, P. H. (1980). Computer-facilitated changes in the management power structure. Accounting, Organizations and Society, 5 (2), 203-216.

Burns, A. (1981). The microchip: Appropriate or inappropriate technology? Chichester: Ellis Harwood.

Christie, B. (1985). Human factors of information technology in the office. Chichester: John Wiley \& Sons.

Davies, L. \& Harvey, W. (1994). Electronic neighbourhoods: Communicating power in computer-based networks. In L. Green \& R. Guinery (Eds.), Framing technology: Society, choice and change (pp. 131142). St. Leonards, NSW: Allen \& Unwin.

Deetz, S. A. (1985). Ethical considerations in cultural research in organizations. In P. J. Frost, L. F. Moore, M. R. Louis, C. C. Lundberg, \& J. Martin (Eds.), Organizational culture (pp. 253-269). Beverly Hills, CA: Sage.

Deetz, S. A. (1990). Forward. In B. D. Sypher (Ed.). Case studies in organizational communication (pp. viii-x). New York: The Guildford Press.

Deetz, S. A. (1991). Representation of interests and the new communication technologies: Issues in democracy and policy. In M. J. Medhurst, A. Gonzales, and T. R. Peterson (Eds.), Communication and the culture of technology (pp. 43-62). Pullman, WA: Washington State University Press.

Deetz, S. A. (2001). Conceptual foundations. In F. M. Jablin \& L. L. Putnam (Eds.), The new handbook of organizational communication: Advances in theory, research, and methods (pp. 3-46). Thousand Oaks, CA: Sage.

Deetz, S. A., Tracy, S. J., \& Simpson, J. L. (2000). Leading organizations through transition: Communication and cultural change. Thousand Oaks, CA: Sage.

DeSanctis, G. \& Fulk, J. (1999). Conclusion: Research, issues and directions. In G. DeSanctis \& J. Fulk (Eds.), Shaping organizational form: Communication, connection and community (pp. 497-502). Thousand Oaks, CA: Sage.

Dewhirst, H. D. (1970-71). Influence of perceived information-sharing norms on communication channel utilization. Academy of Management Journal, 13-14, 305-315. 
Eisenberg, E. M. \& Goodall Jr., H. L. (2001). Organizational communication: Balancing creativity with constraint $\left(3^{\text {rd }}\right.$ ed.). New York: Bedford / St. Martins.

Foucault, M. (1974). The archaeology of knowledge. London: Tavistock Publications.

Fulk, J. \& Collins-Jarvis, L. (2001). Wired meetings: Technological mediation and organizational gatherings. In F. M. Jablin \& L. L. Putnam (Eds.), The new handbook of organizational communication: Advances in theory, research, and methods (pp. 624- 665). Thousand Oaks, CA: Sage.

Fulk, J. \& DeSanctis, G. (1995). Electronic communication and changing organizational forms. Organization Science, 6(4), 337-349.

Goffman, I. (1967). Interaction ritual: Essays in face-to-face behavior. New York: Pantheon.

Goodman, E. H., Griffith, T. L., \& Fenner, D. B. (1990). Understanding technology and the individual in an organizational context. In P. S. Goodman, L. S. Sproull, and Associates (Eds.), Technology and organizations (pp. 45-86). San Francisco: Jossey-Bass.

Green, L. (2001). Technoculture: From alphabet to cybersex. Sydney: Allen \& Unwin.

Habermas, J. (1972). Knowledge and human interest. (J. Shapiro Trans.). Boston: Beacon.

Hamelink, C. J. (1988). The technology gamble. Informatics and public policy: A study of technology choice. Norwood, NJ: Ablex.

Hirschheim, R. A. (1985). Office automation: A social and organizational perspective. New York: John Wiley.

Jablin, F. M. (1987). Formal organization structure. In F. M. Jablin, L. L. Putnam, K. H. Roberts, \& L. W. Porter (Eds.), Handbook of organizational communication: An interdisciplinary perspective (pp. 389419). Newbury Park, CA: Sage.

Johansen, R. \& De Grasse (1992). Computer-based teleconferencing: Effects on work patterns. In K. L. Hutchinson (Ed.), Readings in Organizational communication (pp. 417-426). Dubuque, IA: Wm C. Brown.

Johnson, J. C. (1990). Selecting ethnographic informants. Newbury Park, CA: Sage.

Kerr, E. B. \& Hiltz, S. R. (1982). Computer-mediated communication systems: Status and evaluation. New York: Academic Press Inc.

Kohler, H. (1994). Computer conferencing competence: Methodological contributions to the development of good computer support for human communication at work. In J. H. E. Andriessen \& R. A. Roe (Eds.), Telematics and work (pp. 213-229). Hillsdale, NJ: Lawrence Erlbaum Associates.

Manross, G. G. \& Rice, R. E. (1986). Don't hang up: Organizational diffusion of the intelligent telephone. Information and Management, 10, 161-175.

Mantovani, G. (1994). Is computer-mediated communication intrinsically apt to enhance democracy in organizations? Human Relations, 47 (1), 45-62.

McCracken, G. (1988). The long interview. Newbury Park, CA: Sage.

McLuhan, M. (1969). Interview with Eric Norden: A candid conversation with the high priest of pop cult and metaphysician of media. Playboy, March, 53-62, 64-6, 68, 70, 72, 74, 158.

Morgan, D. (1997). Focus groups as qualitative research ( $2^{\text {nd }}$ ed.). Thousand Oaks, CA: Sage.

Morley, I. E. (1994). Computer supported co-operative work and engineering product design. In J. H. E. Andriessen \& R. A. Roe (Eds.), Telematics and work (pp.231-260). Hillsdale, NJ: Lawrence Erlbaum Associates.

Mumby, D. K. (2001). Power and politics. In F. M. Jablin \& L. L. Putnam (Eds.), The new handbook of organizational communication: Advances in theory, research, and methods (pp. 585-623). Thousand Oaks, CA: Sage. 
Newell, S. Scarbrough, H. \& Swan, J. (2001). From global knowledge management to internal electronic fences: Contradictory outcomes of intranet development. British Journal of Management, 12, 97-111.

Orlikowski, W. J. (1992). The duality of technology: Rethinking the concept of technology in organizations. Organizational Science, 3 (3), 398-427.

Olsen, M. H. \& Lucas Jr., H. C. (1982). The impact of office automation on the organization.: Some implications for research and practice. Communications of the ACM, 25(11), 838-847.

Perse, E. M. \& Courtright, J. A. (1993). Normative images of communication media: Mass and interpersonal channels in the new media environment. Human Communication Research, 19 (4), 485-503.

Pettigrew, A. M. (1972). Information control as a power resource. Sociology, 6, 187-204.

Pfeffer, J. (1981). Power in organizations. Marshfield, MA: Pitman.

Pfeffer, J. \& Salancik, G. (1974). Organizational decision-making as a political process: The case of a university budget. Administration Science Quarterly, 19, 135-151.

Peiro, J. M. \& Prieto, F. (1994). Telematics and organizational structure and processes: An overview. In J. H. E. Andriessen \& R. A. Roe (Eds.), Telematics and work (pp.175-207). Hillsdale, NJ: Lawrence Erlbaum Associates.

Poole, M. C. (1999). Organizational challenges and the new forms. In G. De Sanctis \& J. Fulk (Eds.), Shaping organizational form: Communication, connection and community (pp. 453-471). Thousand Oaks, CA: Sage.

Punch, M. (1986). The politics and ethics of fieldwork. Newbury Park, CA: Sage.

Rice,R. E. \& Shook, D. E. (1988). Access to usage of and outcomes from an electronic messaging system. ACM Transactions on Office Information systems, 6 (3), 255-276.

Rice, R. E. \& Steinfield, C. (1994). Experience with new forms of organizational communication via electronic mail and voice messaging. In J. H. E. Andriessen \& R. A. Roe (Eds.), Telematics and work (pp. 109-137). Hillsdale, NJ: Lawrence Erlbaum Associates.

Rice, R. E. \& Gattiker, U. E. (2001). New media and organizational structuring. In F. M. Jablin \& L. L. Putnam (Eds.), The new handbook of organizational communication: Advances in theory, research, and methods (pp. 544-581). Thousand Oaks, CA: Sage.

Rice, R. E. (1993). Media appropriateness: Using social presence theory to compare traditional and new organizational media. Human Communication Research, 19 (4), 451-484.

Rice, R. E., Hughes, D. \& Love, G. (1989). Usage and outcomes of electronic messaging at an R\&D organization: Situational constraints, job level and media awareness. Office, Technology, People, 5 (1), 141-161.

Robey, D. (1981). Computer information systems and organizational structure. Communications of the $A C M, 24$ (10), 679-687.

Rogers, E. M. (1983). Diffusion of innovations. New York: The Free Press.

Romm, C. T. (1999). Virtual politicking: Playing politics in electronically linked organizations. Cresskill, NJ: Hampton Press.

Ruben, B. D. \& Stewart, L. P. (1998). Communication and human behavior (4 ${ }^{\text {th }}$ ed.). Boston: Allyn \& Bacon.

Ruchinskas, J., Svenning, L., \& Steinfield, C. W. (1990). Video comes to organizational communication. In B. D. Sypher (Ed.), Case studies in organizational communication (pp. 269-281). New York: The Guildford Press.

Schmidt, H. (1985). Technology and employment practices in developing countries. London: Croom Helm.

Schneiderman, B. (1989). Designing the user interface. In T. Forester (Ed.), Computers in the human context (pp. 169). Oxford: Basil Blackwell. 
Stake, R. E. (2000). Case studies. In N. K. Denzin \& Y. S. Guba (Eds.), Handbook of qualitative research ( $2^{\text {nd }}$ ed.) (pp. 435-454). Thousand Oaks, CA: Sage.

Steinfield, C. W. (1990). Computer-mediated communication in the organization: Using electronic mail at Xerox. In B. D. Sypher (Ed.). Case studies in organizational communication (pp. 282-294). New York: The Guildford Press.

Stephens, M. (1998). "Which communications revolution is it anyway?" Journalism and Mass Communication Quarterly, 75, 9-13.

Sypher, B. D., Sypher, H. E., Housel, T. J., \& Booth, R. (1990). The role of communication in automating IBM Lexington. In B. D. Sypher (Ed.), Case studies in organizational communication (pp. 254-265). New York: The Guildford Press.

Taylor, B. C. \& Trujillo, N. (2001). Qualitative research methods. In F. M. Jablin \& L. L. Putnam (Eds.), The new handbook of organizational communication: Advances in theory, research, and methods (pp. 161-194). Thousand Oaks, CA: Sage.

Ward, J. \& Hansen, K. A. (1987). Search strategies in mass communication. New York: Longman.

Wimmer, R. D. \& Dominick, J. R. (2003). Mass media research: An introduction (7th ed.). Belmont, CA: Thompson-Wadsworth.

Yin, R. (1994). Case study research (3rd ed.). Newbury Park, CA: Sage.

Zmud, R. W. (1989). Opportunities for strategic information manipulation through new technology. In J. Fulk \& S. Steinfields (Eds), Organizations and communication technology (pp. 95-116). Newbury Park, CA: Sage.

\section{Biography}

Niranjala D. Weerakkody (Ph D, Rutgers U, NJ, USA) is a Senior Lecturer in Communication Studies at Deakin University. Her current research includes 'examining measures to improve digital television adoption in Australia' (with Associate Professor Wilfred Tremblay of the University of Wisconsin-Whitewater, USA) and 'examining public perceptions and opinions about the use of biometric identifiers in everyday life in the USA, Australia, Malaysia and Sri Lanka' (with Associate Professor Janette Moody of the Citadel, Charleston, NC, USA). 